\title{
CONSTRUCTED WETLANDS AND THEIR IMPLEMENTATION ON PRIVATE AND PUBLIC LAND IN KATHMANDU VALLEY, NEPAL
}

\author{
ZUZANA BOUKALOVÁ ${ }^{1}$, JAN TĔS̆ITEL $^{2,3}$ \& BINOD DAS GURUNG \\ ${ }^{1}$ VODNÍ ZDROJE a.s., Czech Republic \\ ${ }^{2}$ METCENAS o.p.s., Czech Republic \\ ${ }^{3}$ AMBIS a.s., Czech Republic \\ ${ }^{4}$ CISD, Nepal
}

\begin{abstract}
In the year 2018 we were surveying the current situation of the constructed wetlands (CW) in Kathmandu Valley. Nepal and their implementation possibilities on private and public land. We divided the CWs into groups according to the beneficiary type: CWs for schools, CWs for private houses, CWs for bigger communities and CWs for institutions with other than educational purposes (hospitals, monasteries, etc.). We identified two potentially successful $\mathrm{CW}$ models that could be replicated for sustainable wastewater treatment and started the discussion about how the CW could be effectively used for flood protection measures as well. CWs are a strategic natural based technology for Nepal because they are highly efficient in removing organic and insoluble substances and, at the same time, they could be used as a natural based solution for flood prevention. Their construction and operation are both simple and cost-effective. For their management, neither electric power nor sophisticated computers are needed and they do not contain mechanical components that would require repairing and importing. Furthermore, they work very well regardless of the season, precipitation and temperature. Nevertheless, it must be noticed that CWs do not work without any attention - the operator's participation is required for their good performance.

Keywords: water management, constructed wetlands, pollution control, floods, land management, Nepal.
\end{abstract}

\section{INTRODUCTION}

Discharge of untreated wastewater into rivers, lakes or any other water body is a common practice in most of the developing countries, including Nepal. In the Kathmandu Valley, all the urban rivers are converted into open sewer canals due to the discharge of untreated wastewater from households and in some cases industrial places. The concept of wastewater treatment or recycling is taken as unaffordable technology, so expensive, technologically complicated and impossible to maintain. In the last century, four sewerage treatment plants were constructed around the Kathmandu Valley, but are no longer functioning. Due to the failure of these large treatment plants, small and decentralized treatment plants and constructed wetlands are in the centre of interest [1].

In addition to that, CWs rank among natural based solution that have another purpose in the cities and the landscape: they can be successfully used for flood protection.

\section{CONSTRUCTED WETLANDS IN KATHMANDU VALLEY}

Constructed wetlands $(\mathrm{CW})$ are designed and built in such a way to take advantage of the processes that occur in natural wetlands for wastewater treatment. In Nepal, less sophisticated $\mathrm{CW}$ types are used that require little maintenance and space. In these CWs, wastewater carrying organic pollution first undergoes primary treatment and then it passes into the secondary treatment area, which is typically a biofilter or a constructed wetland. The primary treatment typically consists of a screen, sand and gravel trap (if rainwater runoff is treated as 
well) and, at the end of the process, a septic tank may be included. The primary treatment requires certain level of maintenance - the screen needs to be cleaned, the sludge removed, etc. - whereas the operation of the root bed needs virtually no interventions. If maintenance of the primary treatment is neglected, it stops working. As a result, all the sludge enters the root bed, the performance of the $\mathrm{CW}$ declines until it eventually stops functioning.

The conditions for the construction and operation of CWs are ideal in Nepal, in the Kathmandu Valley. Another factor supporting the introduction of CWs there is the progressive local groundwater level decline due to the migration boom that started at the end of the last century. As a result, lasting shortage of drinking and sanitary waters takes place in all big cities in the Valley [2]. Thus, the treated wastewater could be infiltrated into the rock formations to help stabilise groundwater levels in the shallow aquifer.

CWs started to be built in Nepal by the ENPHO non-profit organisation. In 1997, the first $\mathrm{CW}$ was built for the Dhulikhel hospital, which is still working thanks to a well-defined cooperation policy with the local authorities [3]. In addition, similar CWs were set up also for housing areas near the hospital.

However, successful CW introduction in Nepal is far from being granted. Everything depends on the kind of entity that receives and runs the CW. Legislation and standards in Nepal are week and therefore wastewater treatment is not a priority for city governments, private institutions and industries. Despite $\mathrm{CW}$ being a low-cost technology it might be difficult to convince people to pay for their wastewater treatment. Moreover, gravel, sand and reeds might not be locally available for construction. The key issue is as well "who" takes the responsibility for the CW maintenance and how this responsibility is defined and granted.

In surveying the current situation in the Kathmandu Valley, we divided the CWs into the following groups according to the beneficiary type, based on the available information and the visits we made:

a) CWs for schools;

b) CWs for private houses;

c) CWs for bigger communities;

d) CWs for institutions with other than educational purposes (hospitals, monasteries, etc.).

The CWs we visited were usually subsurface flow systems, only occasionally combined with free water surface system [4]. CWs of horizontal-type CW, vertical-type CW, or mixed were identified [5].

An example of the (a) group may be a fully functional horizontal-type CW for the Shuvatara International School (private boarding high school) in Lalitpur (Fig. 1), which is used for treatment of wastewater from toilets and other school facilities for approx. 700 students.

The $\mathrm{CW}$ is fully functional and has been in operation for 18 years. Its structure is entirely standard - the CW is composed of a sedimentation tank where the separation of the solid and liquid parts takes place, followed by an anaerobic baffled reactor and constructed wetlands with emerged vegetation. The operation of the $\mathrm{CW}$ is supervised by a responsible person and the performance of the wetland is regularly checked. If needed, regeneration of individual treatment stages is undertaken. The water flowing out from the CW (Fig. 2) is colourless, odourless and clear, and is infiltrated through drainage piping into agricultural soil outside the school premises.

An example of the (b) group is a private house in Dallu, Swoyambhu where a Montessori kindergarten is based as well. In terms of water supply, the building is fully self-sufficient. 


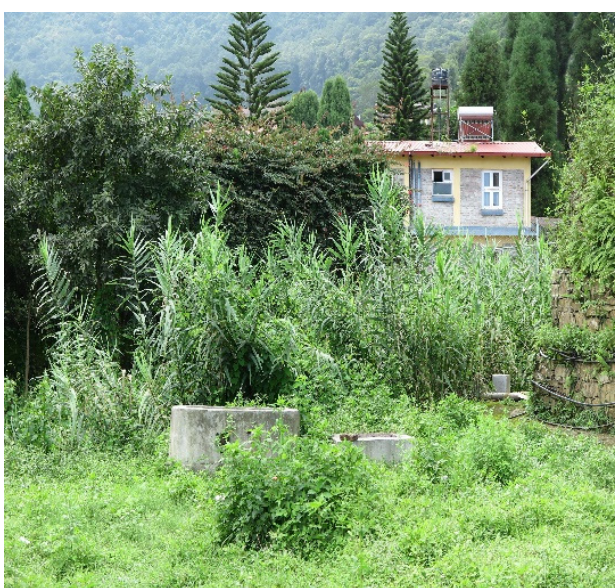

Figure 1: Shuvatara CW.

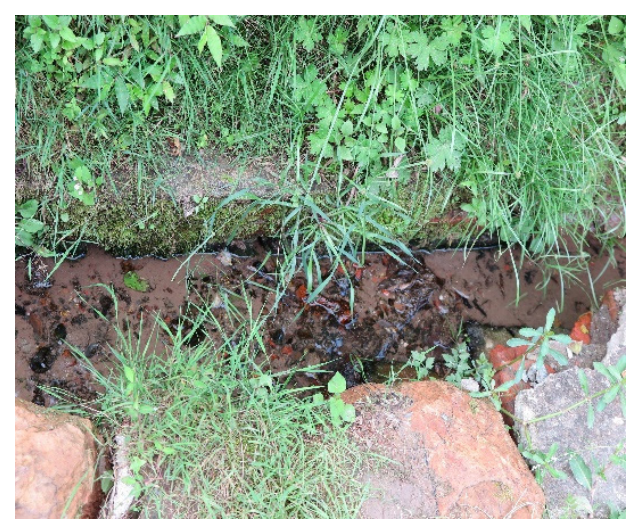

Figure 2: Water flowing out from the CW.

While drinking water is obtained through rain harvesting (Fig. 3), sanitary water is provided by a vertical-type CW partly combined with a horizontal wetland (Fig. 4) for treating wastewater coming from toilets and other facilities located in the building, which is used by up to 80 residents including children. When the kindergarten is in operation, the estimated amount of wastewater is approximately $700 \mathrm{l} /$ day and the amount of sanitary water obtained through the $\mathrm{CW}$ for washing, toilet flushing, and gardening is $500 \mathrm{l} / \mathrm{day}$. In case the $\mathrm{CW}$ produces an excess of treated water which is not further used to cover the place's demands, this excess is drained away into the sewerage system through an overflow. The $\mathrm{CW}$ is managed, and its performance checked by the house owner.

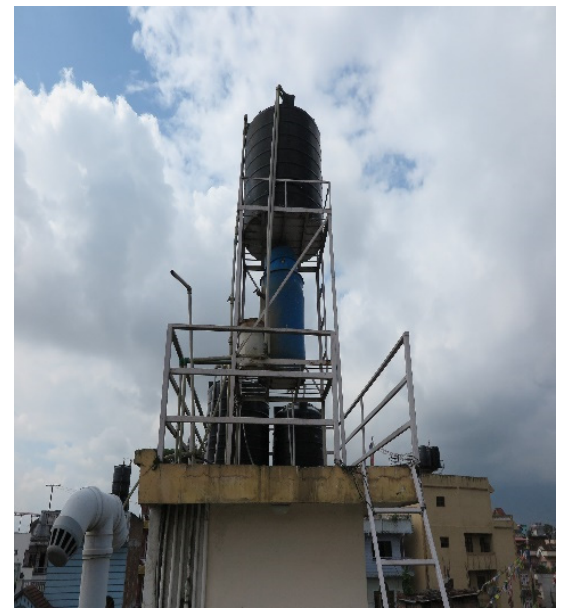

Figure 3: Dallu house, the rainwater harvesting.

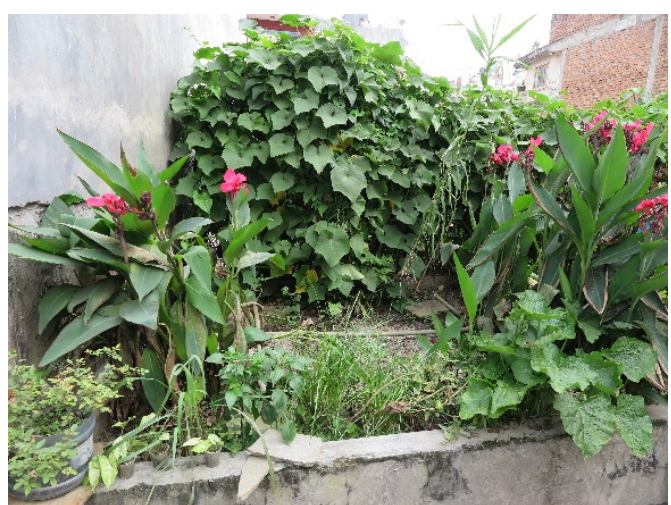

Figure 4: Dallu house: horizontal wetland. 
As regards the CWs for bigger communities (case (c)), we have not been able to document a fully functional facility.

The CW for the Kirtipur community was in operation only to a limited extent. In case of the Dobighat community, which lives in a housing-estate-type building with six floors, we did not even locate the supposed CW. None of the present residents knew about the existence of the $\mathrm{CW}$ or the place where it should supposedly be located. In the house, only a rainwater harvesting system for sanitary water supply was in place.

The CW on the premises of the Kirtipur community (44 poor displaced families from other areas after widening road activities and other reasons, living in small houses built by the Lumanti non-profit organisation as a complex including a CW and a rain harvesting system) was in operation. However, it was not maintained and, as a result, its performance was limited. The basic principle by which a CW works is wastewater flowing through a permeable filtering layer planted with wetland plants, where organic pollution is removed by a combination of physical, chemical, and biological processes. Prior to entering the constructed wetland itself, wastewater must always be pre-treated mechanically, which is highly important for this kind of treatment in terms of separation of the solid and liquid parts. In case of the Kirtipur community, the second treatment stage consisted of a wetland located in the centre of the lower square within the housing estate (Fig. 6), and of a smaller complementary wetland for final treatment at the outflow from the premises (Fig. 5).

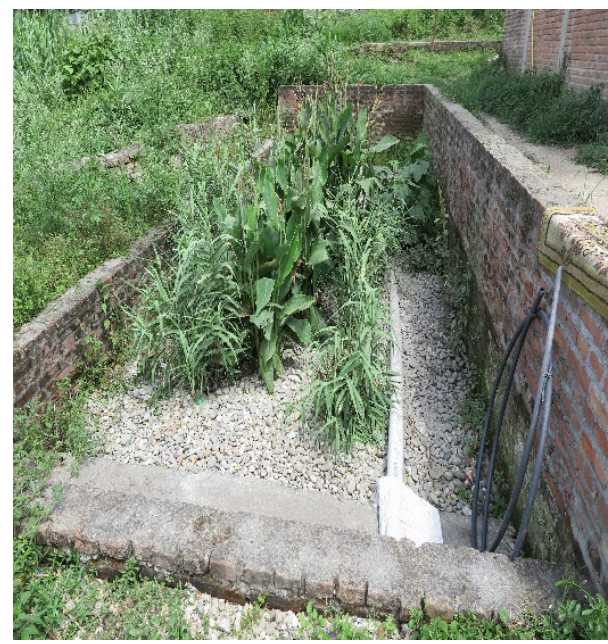

Figure 5: Kirtipur community $\mathrm{CW}$ : complementary wetland.

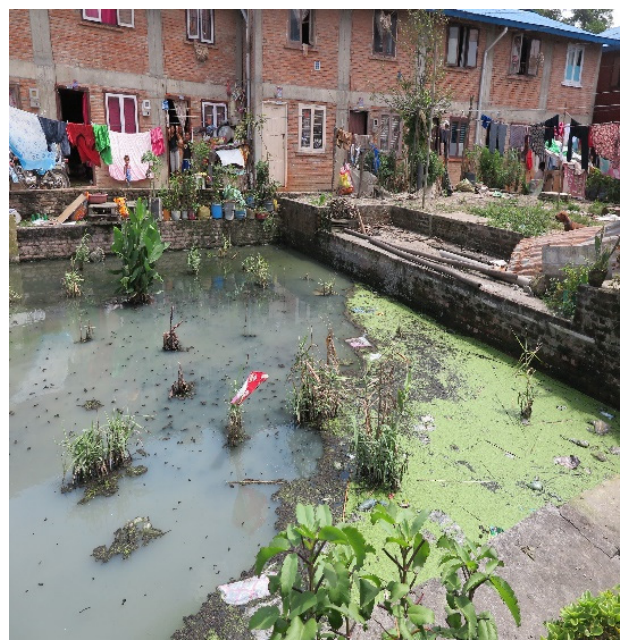

Figure 6: Kirtipur community CW: main wetland area.

At present, rainwater, secondary garbage, plastic films, food packaging paper, etc. are accumulating in the main part of the area for the second stage treatment, which has now turned into a shallow pool of water with only a few emerging plants. Based on the low level of drainage of this reservoir (which was previously a wetland too) into the existing wetland, it may be assumed that this secondary pollution contributed to the blocking of pipes conveying water into the active filter bed, or even to its clogging. The filter bed of the existing wetland for final treatment is made of gravel layers of different grain sizes. Water passes through the filter bed only to a limited extent, and since plants are scarce in this wetland and 
therefore the cleaning capacity of their root systems is limited too, water flowing from the $\mathrm{CW}$ is turbid, although without noticeable odour. The treated wastewater is not used by the community. Instead, it freely flows onto somebody else's agricultural land where it is used for irrigation during rice growing season.

The community has no person directly responsible for the operation of the $\mathrm{CW}$. When we asked why the pieces of garbage were not removed from the area for second-stage treatment and further contamination was not prevented, we were told that contact with garbage was impure and forbidden for their caste. External services are always contracted for the removal of the matter separated in the septic tank and paid for from common funds. The debate with the community's representatives showed that no in-depth training on CW maintenance had been provided during the handover of the housing complex.

The case (d) CWs for institutions with other than educational purposes:

A CW for hospital-like institutions is documented by a successful implementation of the system at the Dhulikhel hospital (Fig. 7). In monasteries, wastewater treatment is apparently not a priority and their attitude may vary. In case of the Kopan monastery, a monastery guardian informed us about the structure of the $\mathrm{CW}$, which was originally intended for sanitary water supply to another monastery lying downhill. We did not manage to contact anyone more qualified in the Kopan monastery (Fig. 8). The CW allegedly did never fully work because the outflow drain cut across private land where its unobstructedness was neither ensured nor dealt with. After 5 years of operation, when wastewater did not reach the originally intended area, the $\mathrm{CW}$ was cancelled and wastewater continues to be drained into the sewerage system.

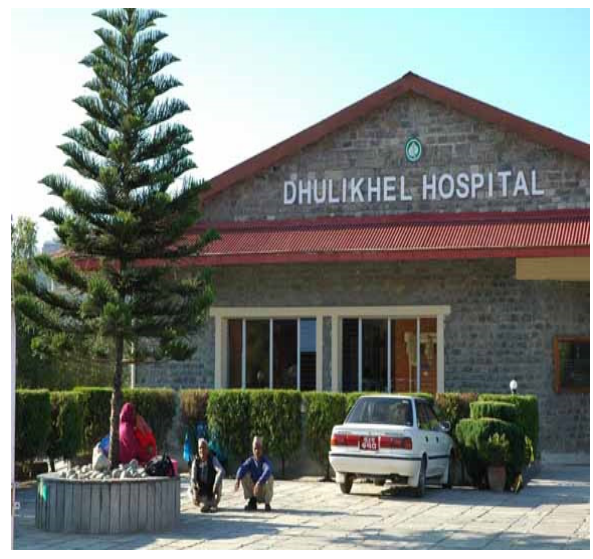

Figure 7: Dhulikhel hospital.

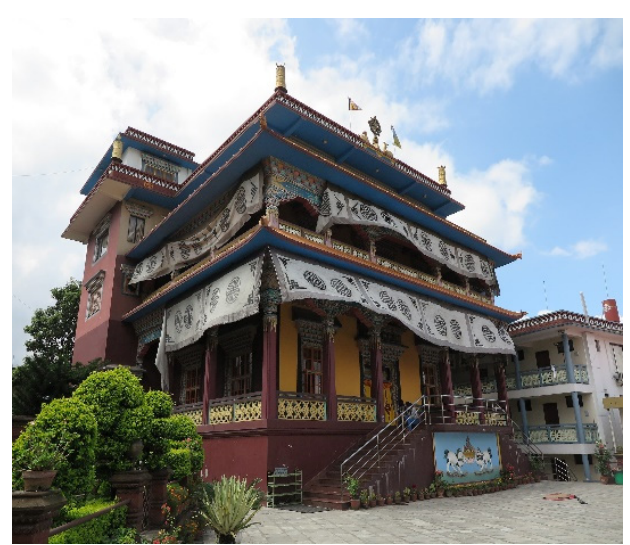

Figure 8: Kopan monastery.

\section{ROLE OF CONSTRUCTED WETLAND IN WASTE WATER MANAGEMENT}

In surveying the various CW types used in practice in the Kathmandu Valley, we have identified two potentially successful $\mathrm{CW}$ models that could be replicated for sustainable wastewater treatment. The first is type (a) that is CWs for schools, and the other is type (b) CWs for private houses.

In case of private houses (which are almost always at least upper-middle-class houses), drinking and sanitary water demands are fully covered through the $\mathrm{CW}$ and rainwater harvesting systems intended for the residents' own use or, in some cases, for the use of a 
resident group including neighbours. A drawback to implementing this double system might be locally reduced infiltration of rainwater and treated wastewater into the rock formations and the aquifer. This could result in further groundwater level decline in the area, which in turn might compromise water sources for socially vulnerable residents, who are accustomed to use the hiti (water spouts) as their long-term sources of water. The house of interest in Dallu, for instance, stands right above dried-out water spouts that do not provide water even at the very end of the monsoon season (beginning of September 2018). As a result, those residents who cannot afford to build their own house including a $\mathrm{CW}$ - rainwater harvesting system depend on purchasing drinking water in barrels and sanitary water from tanks.

CW construction for schools appears to be the best solution for the Kathmandu Valley. Schools typically have enough space for the construction of a $\mathrm{CW}$ and, thanks to the number of students, also have a sufficient amount of wastewater from toilets and other facilities. Here, CWs also play an educational role: students can be directly involved in the maintenance and performance monitoring. The $\mathrm{CW}$ helps them understand what the water cycle means, how water flows in nature and, therefore, that water in all wells that tap into one aquifer is still the same water, and that excessive water extraction in a given source area compromises the availability of water for people in lower-lying communities. They may then use this experience in the place of their residence. In addition, school management or its owner do not change often. As a result, knowledge about the $\mathrm{CW}$ location and its proper maintenance remains over years. What is also crucial is the fact that schools (at least the richer, which is private schools) do not need to retain the treated wastewater on their premises. Instead, they drain it into the rock formations through drainage piping; the direct use of an infiltration facility is also possible.

The implementation of CWs for hospitals is also expected to be potentially successful, as in the case of the Dhulikhel site. However, since wastewater from hospitals may be expected to carry, apart from organic pollutants, also contamination by various types of pharmaceuticals, we do not recommend further implementation of CWs for hospitals to produce sanitary water from the treated wastewater. However, such CWs would be suitable for subsequent infiltration of the treated wastewater into the rock aquifer, as natural attenuation of pharmaceuticals in the rock formations can be relied on [6].

\section{ROLE OF CONSTRUCTED WETLAND IN FLOODS PREVENTION}

The CWs in Nepal could in some cases play as well the role of natural based solution for flood protection. At present, Nepal needs to focus on flood prevention and public awareness; define a land use policy with clearly delimited responsibilities and tasks; and set up a fair method of flood damage compensation.

The main problem of big cities in the Kathmandu Valley is lack of land and constant inflow of migrants from rural areas. All suitable and even less suitable land plots, which could be used for the CW use, are being built up. There is a trend towards purchasing community land or its direct illegal occupation (e.g. along rivers in big cities) and converting farmland, historical ponds (Pokhari) and gardens into building plots. There is neither room nor interest of the inhabitants in CWs to be used for flood protection at municipal level.

Nature based flood control measures can protect riverside communities from floods and in some cases could be "in the right place at the right time", as for example in the area of Marga Tole - 10 community area, Kathmandu, in the vicinity of Baghmati river. However, in these areas poor people and migrants live in slums, mostly on land they do not directly own, and so their efforts to protect their dwellings are limited to political protests and aid applications; their own investments are out of question. In addition, land-use planning and environmental education are insufficient in Nepal and have not become a priority, yet. 


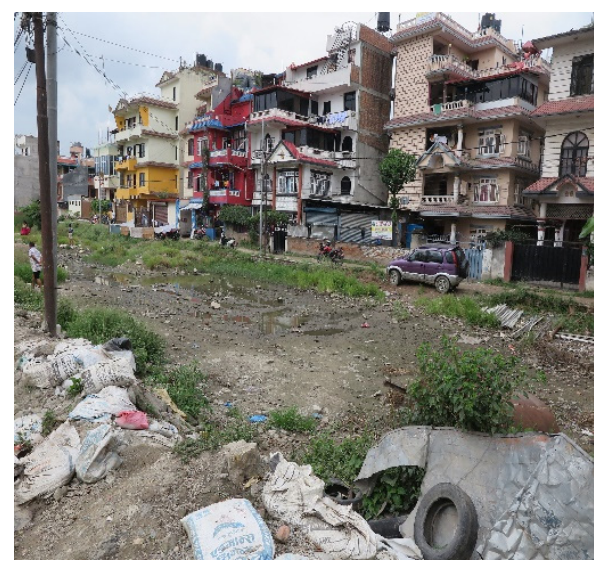

Figure 9: Buddha Marga Tole - 10 community area.

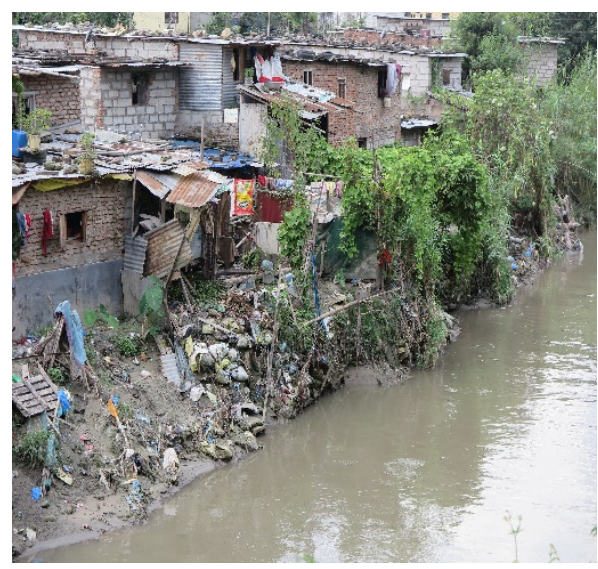

Figure 10: Slum on the riverside of Bagmati river, Kathmandu.

However, CWs could become an important element in establishing a sustainable flood protection system while implementing the new Disaster Reduction Act, which was passed by the Nepalese parliament on 24th September 2017. Simultaneously, the whole concept of approaching the flood issues is changing, so that the debate about the usefulness of CWs in flood protection will be subject for further research.

There is a shift evident in the pertinent professional literature as to the approach to manage floods. The original one, stressing prevention and employing primarily science and technology, implemented as a rule by use of top-down manner by the state administration, has been recently complemented by the approach coining the slogan "living with floods". The latter builds frequently on local knowledge and considers (repeated) floods as a normal part of life [7], [8].

\section{CONCLUSION}

The findings mentioned in Section 3 will be built upon in the upcoming field survey in the year 2019, that will focus on the use of CWs in the Kathmandu Valley metropolitan areas (for wastewater treatment and reuse). In the Kathmandu Valley, a preliminary site has been chosen for establishing a model CW on municipal land (Ward Office of Lalitpur Submetropolitan City), where sufficient amounts of wastewater as well as suitable space and a responsible person to oversee the operation of the $\mathrm{CW}$ will be ensured. Strategical is as well to involve Ward Office of local government to the activities, so that would be easier to influence local and regional policy and water management practices. The selection of the governmental place for the $\mathrm{CW}$ will have as well the positive impacts on the replication of the CWs in other areas in the future.

\section{ACKNOWLEDGEMENTS}

This paper was developed thanks to the EUEKA project E! 12219 BIORESET, co-financed by the Ministry of Education, Young and Sports, Czech Republic (50\%) and organization VODNÍ ZDROJE a.s. and thanks to the COST project "LAND4FLOOD: Implementation of nature-based retention measures on private land", financed by the Ministry of Education, Young and Sports, Czech Republic. 


\section{REFERENCES}

[1] Shrestha, R.R., Haberl, R., Laber, J., Manandhar, R. \& Mader, J., Application of constructed wetlands for wastewater treatment in Nepal. Water Science and Technology, 44(11-12), pp. 381-386, 2009.

[2] Boukalova, Z., Těšitel, J., Hrkal, Z. \& Kahuda, D., Artificial infiltration as integrated water resources management tool. Proceedings of the Twelfth Water Pollution Conference, Algarve, Portugal, pp. 201-210, 2014.

[3] ENPHO, Constructed wetlands in Nepal. ENPHO Magazine, World Water Day Issue, 2004.

[4] Fonder, N. \& Tom Headley, T., The taxonomy of treatment wetlands: A proposed classification and nomenclature system. Ecological Engineering, 51, pp. 203-211, 2013. www.elsevier.com/locate/ecoleng.

[5] Yalcuk, A. \& Ugurlu, A., Comparison of horizontal and vertical constructed wetland systems for landfill leachate treatment. Bioresource Technology, 100, pp. 2521-2526, 2009. www.elsevier.com/locate/biortech.

[6] Rozman, D., Hrkal, Z., Eckhardt, P., Novotná, E. \& Boukalová, Z., Pharmaceuticals in ground waters: A case study of the psychiatric hospital at Horní Beřkovice, Czech Republic. Environmental Earth Sciences, 73(7), pp. 3775-3784, 2014. http://link.springer.com/article/10.1007/s12665-014-3663-1.

[7] Ehlert, J., Beautiful Flood. Environmental Knowledge and Agrarian Change in the Mekong Delta, Vietnam. LIT Verlag: Vienna and Berlin, 2012.

[8] Fitton, S.L., Moncaster, A. \& Guthire, P., Investigating the social value of the Ripon rivers flood alleviation scheme. Journal of Flood Risk Management, 9, pp. 370-378, 2015. 